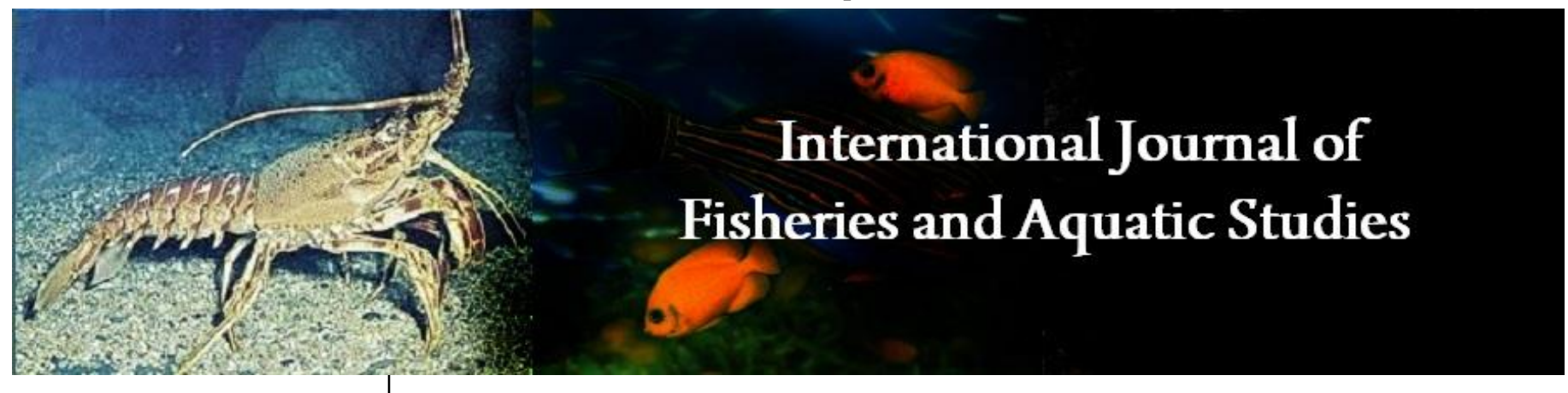

E-ISSN: 2347-5129

P-ISSN: 2394-0506

(ICV-Poland) Impact Value: 5.62

(GIF) Impact Factor: 0.549

IJFAS 2021; 9(6): 23-29

(C) 2021 IJFAS

www.fisheriesjournal.com

Received: 12-09-2021

Accepted: 15-10-2021

Timothy Odende

a. Department of Environmental

Sciences, Maseno University,

P.O. Box Private Bag,

Maseno, Kenya

b. Fisheries Directorate, Busia

County, P.O. Box $142-50400$

Busia, Kenya

Albert Long' ora

Department of Environmental

Sciences, Maseno University,

P.O. Box Private Bag, Maseno,

Kenya

Erick 0 Ogello

Department of Animal and

Fisheries Science, Maseno

University, P.O. Box Private

Bag, Maseno, Kenya

Fonda Jane Awuor

Kenya Marine and Fisheries

Research Institute, P.O. Box

1881- 40100 Kisumu, Kenya

Corresponding Author:

Timothy Odende

a. Department of Environmental Sciences, Maseno University,

P.O. Box Private Bag,

Maseno, Kenya

b. Fisheries Directorate, Busia

County, P.O. Box $142-50400$

Busia, Kenya

\section{Effects of fisheries policy implementation strategies on regulatory compliance in the small-scale fisheries sector in Lake Victoria: A case study of Busia County, Kenya}

\author{
Timothy Odende, Albert Long Ora, Erick O Ogello and Fonda Jane Awuor
}

DOI: https://doi.org/10.22271/fish.2021.v9.i6a.2582

\begin{abstract}
Lake Victoria is an integral part of Kenya's food production system. Fisheries policies and regulations have been formulated and implemented for sustainable management of the lake's resources, but the lake's ecological health continues to deteriorate. This study investigated the effect of fisheries policy implementation strategies on regulatory compliance in the small-scale fisheries sector in Lake Victoria, in Busia County, Kenya. A descriptive and explanatory research design was applied to a cross-section of randomly selected 324 respondents. Findings from the study show that legitimacy was not significant in compliance on closed seasons and mesh size regulations $(\mathrm{p}>0.05)$. Examining the fishery's specific conditions is required to debate the importance of non-recognized regulations, why this happens, and how to strengthen the procedures to make them legal. The study further indicated that fishermen with consistent income do not violate the regulations $(\mathrm{p}<0.05)$. Government commitment is thus required to implement long-term alternative livelihood strategies to increase compliance with fisheries regulations.
\end{abstract}

Keywords: Fisheries policies, Lake Victoria, alternative livelihoods, compliance to regulations, Busia County

\section{Introduction}

Small-scale capture fisheries have gained international recognition because of their essential contribution to global food security and poverty alleviation. These fisheries are frequently open to the public, with no restrictions on entry or total capture. How individuals act and interact in such inadequate institutional environments is critical to whether or not fish stocks can be sustained, depicting the tragedy of the commons ${ }^{[1]}$. Poor people are most commonly exposed to natural resource deterioration because they are forced to exploit their surroundings for short-term survival [2]. Natural resources are frequently the shared pool resource type, implying overexploitation issues that can be difficult to manage. For many impoverished people, fish is an essential source of protein ${ }^{[3]}$, and it is a resource to which the prior explanation applies.

Lake Victoria is the world's second largest freshwater lake with significant socioeconomic and environmental benefits to the riparian communities. Lake Victoria accounts for over $80 \%$ of freshwater fish production in Kenya and directly employs about 1.2 million people in the fisheries value chain ${ }^{[1,4,5]}$. With the contribution of about $1 \%$ to the country's yearly Gross Domestic Product (GDP), fisheries have become an important source of food and nutrition security and employment for the common population. In Kenya, the fisheries sector has been captured significantly in the national vision 2030 as one of the elements of the economic pillar for food nutrition and livelihood security, which also features in the national 'Big Four Agenda' ${ }^{[6]}$. However, Lake Victoria and its ecological resources are under severe stress due to the growing human population, which leads to unsustainable exploitation ${ }^{[7]}$. For example, Lake Victoria's fish output fell from 98,150 tons in 2018 to 90,742 tons in $2019^{\text {[6] }}$. This was the lowest yield in the previous five years, due to a myriad of problems including overfishing, excessive pollution levels, and unsustainable fishing practices ${ }^{[8]}$.

Increase in human population in the lake region has caused an increase in the number of fishers, fish crafts, and fishing illegalities, hence the need to control fishing effort, limiting entry into the fishery through species-specific licensing of fishing vessels and fishers, and 
promoting alternative livelihood in fishing communities to reduce pressure ${ }^{[9]}$. As more fishermen enter the fishery, the demand for the fishery has increased. As a result, the lake has been under a lot of pressure to meet market demand, which has reduced catch per unit effort (CPUE) and the size of fish landed. This has forced fishers to participate in illegal fishing practices such as using illegal gear (mostly undersize nets and forbidden fishing methods such beach seining, poisoning, trawling and fishing in restricted areas.

The Lake Victoria Fisheries Service (LVFS) was established in the late 1920s to manage the lake's fishery and conducted the first fisheries survey ${ }^{[10]}$. The first Lake Victoria Fisheries Management Plan (FMP I) was designed in 2001 and implemented from 2005 to 2008. From 2009 to 2014, FMP 2 was implemented. The current FMP 3 (2015-2020) was created to remedy the shortcomings of the previous two programs. The Fisheries Management and Development Act (FMDA) of 2016 lays out the framework for managing all fisheries resources in the country. Based on the FMDA, policies and regulations with respective implementation strategies have been proposed to operationalize the Act. However, the health of Lake Victoria ecosystem continues to weaken and this threatens biodiversity and human livelihoods that depend directly or indirectly on the lake. The big question is whether the policy implementation strategies are faulty or the policies themselves, which is the central focus of this study.

Kenya adopted a new constitution in 2010, giving County governments absolute power over fisheries functions. As a result, some counties have devised management techniques tailored to their needs. For example, Busia County has adopted the Aggregated Aquaculture Production Parks "Aqua Parks" for land-based aquaculture production and cage culture production. The "Aquapark Model" is a production model with a concentration of production units in one area. The production is synchronised to ensure consistent supply of fish throughout a growing season. In most cases, the production units (usually earthen ponds or fish cages) are community owned. The technique has enhanced aquaculture production in the county while also engaging youths who would otherwise engage in illegal fishing. The county has also enforced a voluntary weekend ban which resulted in a $2.6 \%$ rise in fisheries production in $2019^{\text {[11] }}$.

The majority of empirical studies conducted in recent years have focused on understanding the effects of fishing on fish stocks, supporting the fishery to ensure optimum economic benefits, landing site infrastructure, improving compliance with fisheries regulation, and long-term management of Lake Victoria's fisheries resource. A study on fisheries regulatory compliance in Tanzania provides empirical evidence on potential motives for fishermen in Lake Victoria to comply or break the laws ${ }^{[12]}$. However, the study suffers from the flaw of focusing solely on the minimum mesh-size regulation, implying a paucity of data on other tactics like closed seasons and beach seining. Etiegni et al. ${ }^{[13]}$ investigated the causes of illicit fishing and discovered that economic situation, and insufficient enforcement, contribute to low compliance with fisheries rules, resulting in increased degradation of the lake ecology. Understanding the motivations that drive fishers to break the rules and how they relate to the setting is critical to improving future compliance and preserving decreasing fish stocks. The current study adds to the body of knowledge by examining the impact of policy implementation strategies on regulatory compliance in a developing country. This study investigated the effect of fisheries policy implementation strategies on regulatory compliance in the small-scale fisheries sector in Lake Victoria, in Busia County, Kenya.

\section{Materials and methods Study Area Topography}

The research was conducted in Busia County, located in Western Kenya between the latitudes of $0043^{\prime} \mathrm{N}$ and $34015^{\prime} \mathrm{E}$, with the majority of the county falling inside the Lake Victoria Basin. Busia's altitude varies, rising from around 1,130 meters above sea level near Lake Victoria's shoreline to about 1,500 meters in the Samia and North Teso Hills.

Demographics and Economic activities

Busia County has a total population of 893,681 people, with 426,252 females and 467,401 males. The population density in the county is 527 people per square mile, with an average household size of 4.5 people ${ }^{[15]}$. The main economic activities of Busia County are agriculture, fishing, and trading. Busia County hosts one of the largest fish markets in East Africa, where fish and fish products converge and are dispersed to many East African Countries. Busia and Malaba towns, which serve as border crossing sites between Kenya and Uganda, are vibrant trading towns where fish and fish products are handled. As a result, cross-border fish commerce between Kenya and Uganda (and the East Africa region) is more accessible and expands market access for fish traders [14, 15]. The fisheries sector in Busia County offers food, nutrition, work, and income to a hundred million people while also bringing in billions in foreign exchange. In 2019, inland capture fisheries contributed 5 million tons of the County's total fish production valued at 5 million USD, with Lake Victoria being the primary source. In the same reference period, aquaculture increased by $66.4 \%$ from the previous year. Capture fisheries production grew by $2.6 \%$ due to the weekend restriction, which allowed smaller fish to reproduce and thrive, as well as the introduction of fish cages, which allowed fishermen to shift to open-water aquaculture, relieving strain on capture fisheries.

\section{Research design}

This study employed both descriptive and explanatory research designs. A cross-sectional survey was used to collect data. A survey is a useful tool for sociological description since it allows for producing remarkable details and information about a huge heterogeneous population and a wide range of topics in the questions.

\section{Sampling and sample size determination}

Five key criteria guided the site selection i.e., 1) the economic dominance of fishing, 2) the presence of high population densities of communities that rely on the Lake Victoria fisheries, 3) adequate marketing prospects, 4) existing infrastructure, and 5) the adoption of county-specific strategies such as closed weekends and the Aqua Park concept. Busia County offers chances for protecting and using fishery resources responsibly, as well as the Aqua Park model which combines fish cage and pond-based aquaculture systems for easier management and increased aquaculture productivity. Busia county was first identified, and within it, two sub-counties with a total of 20 beaches were selected. Automated randomization utilizing the RAND Function in Microsoft Excel was used to recruit the 324 respondents, including fishermen, boat owners, fish traders, fish processing 
establishments, local gear makers/repairers, and fishing and equipment dealers.

\section{Data collection}

The survey's first part included familiarizing with the research area and the recruitment and training of enumerators and consultations with fisheries extension service professionals, provincial administrators, and other local authorities. These activities took place at the same time as the research tool's pre-testing. The data for this study covered thirteen landing beaches in Busia County (Fig. 1). Beaches that were inaccessible were excluded from the sample. Each landing beach captured variability in various market conditions (such as market accessibility, infrastructure etc.,), fish species landed, and population size.

The study was conducted in September 2021 using face-toface interviews with structured questionnaires that were digitized in Open Data Kit Suite (ODK). The survey collected data on respondents' (i) socio-demographics, (ii) financial characteristics, (iii) knowledge on regulations, (iv) perceptions of deterrence variables, (v) personal compliance behavior and other's compliance behavior (vi) perceptions of social influence and (vii) perceptions on viable sustainable alternative livelihood. The data was qualified through Key Informant Interviews (KIIs) and Focused Group Discussions (FGDs) with various stakeholders giving in-depth investigations of the subject matter and providing more information not provided in the survey. Beach Management Units (BMUs) chairmen, National Environment Management Authority, Kenya Fisheries Service, Kenya Wildlife Service, Nature Kenya, Kenya Marine and Fisheries Research Institute, Beach Management Network chairman, Kenya Coast Guard Service, Busia County Fisheries Department, and Samia sub county administrator participated in three focus group discussions (i.e. small groups in several rounds of interviews as a Covid-19 mitigation measure) to triangulate and interpret results from the survey.

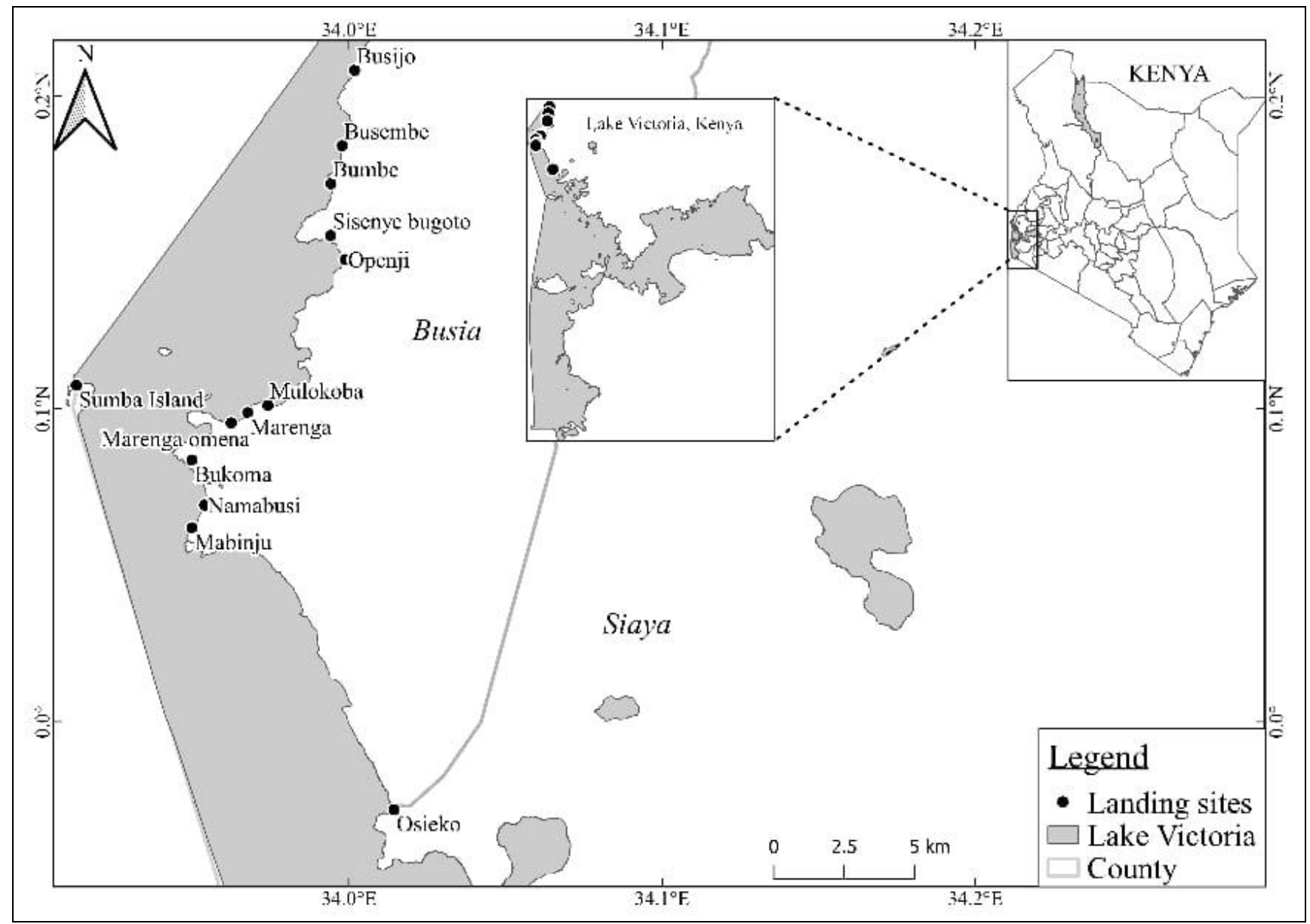

Fig 1: Map indicating each landing site where the study was carried out

\section{Statistical Procedures}

The theoretical model that was followed is the one that extends the neoclassical utilitarian model of the form:

$V_{i}=f\left(F_{i}, K_{i}, L_{i}, S_{i}, X\right)$

Where:

$V_{i=V i o l a t i o n}$; is the dependent variable where $1=$ violation and $0=$ non violation

$F_{i=\text { The financial incentive to violate, }}$
$K_{i}$ a vector of individual's knowledge about the regulations

$L_{i=}$ a vector of variables trying to capture perceived regulatory legitimacy,

$S_{i}=$ is a vector of social influence variables such as social control, and perception about others compliance

$X_{\text {= personal characteristics. }}$.

Because there are differences in each dependent variables i.e., closed seasons, beach seine, and mesh size), each was regressed independently as a dependent variable. The 
justification for having different models was to establish a robust model and avoid bias in classifying the explanatory variables. Therefore, each dependent variable was regressed against the independent variables.

\section{Data Analysis and Presentation}

Qualitative data coding was done through the proper code plan for qualitative responses. Data was processed using STATA version 15.1. Descriptive analysis was done using means, standard deviation, and frequency distribution of responses. Factor analysis procedure was used mainly for data reduction purposes. A Probit model was used to estimate the effect of each of the independent variables on compliance. Inferential statistics were done using Chi-square $\left(\chi^{2}\right)$ test of goodness of fit. All data analyzed was considered significant at 0.05 level of significance.

\section{Results and Discussion}

Table 1 shows the breakdown of interviewed respondents by sub-county, with fishermen accounting for the majority.

Table 1: Distribution of Respondents interviewed

\begin{tabular}{|c|c|c|c|c|c|}
\hline Sub county & Fishermen & Fish traders/fish monger & Boat owners & Local gear makers/repairers & Fishing and equipment dealers \\
\hline Samia & 25 & 15 & 10 & 8 & 3 \\
\hline Bunyala & 117 & 69 & 38 & 20 & 3 \\
\hline Total & 158 & 84 & 48 & 28 & 6 \\
\hline
\end{tabular}

\section{Descriptive Statistics}

The descriptive statistics are reported in Table 2. The sample consists of 324 respondents, of whom most (40\%) were between the ages $36-45$, implying that the fisher community comprises workers in the active middle age category. This age bracket is deemed the most productive age with regards to capital and energy to work optimally. Fishing is still one of the most significant activities in the Busia community, but young people have been sluggish to take it up. To that end, targeted interventions are necessary to sensitize younger and less experienced individuals among the fisher community to effectively manage the fisheries resources and embrace possible sustainable livelihood options. Furthermore, the gender composition of the respondents indicated that male respondents accounted for $78 \%$. In comparison, the female respondents accounted for $22 \%$, indicating that the fishery sector is male-dominated due to its labor-intensive nature. However, females dominate fish trade and processing nodes of the value chain and corroborate the findings of Awuor et al. ${ }^{[16]}$.

Most of the respondents (86\%) were married, with an average household size of 4-7 family members, implying a large family to feed. Similarly, the population census reported an average household size of 4.5 people ${ }^{[8]}$. Education is an essential catalyst for societal development. The majority of the responders $(60 \%)$ had completed primary school. This means that the fishing community is dominated by an illiterate society, as corroborated by the studies of Yongo et al. ${ }^{[17]}$ in other beaches of Lake Victoria. The level of education a person has impacts their capacity to make decisions and acquire necessary skills. Education is thought to speed up the perception, interpretation, and response to new knowledge and the adoption of new technologies and implementation of policies. According to the study, inadequate literacy prevents fisherfolk from expanding their businesses and taking advantage of government and development partner assistance programs. Furthermore, higher levels of formal education might lead to more appealing job prospects in the fishing community.

Of those interviewed, $49 \%$ were fishermen. As indicated, the fishing community in the study area comprises people of diverse ethnic backgrounds, all of whom derive their livelihoods from fishing or fish trading. The major ethnic groups encountered during the survey were from the Luhya (86\%) followed by the Luo (13\%). Only a relatively small percentage comprised Somalis and Kalenjins, who were attracted to the lake for commercial gain.

Table 2: Respondents Summary Statistics

\begin{tabular}{|c|c|c|c|}
\hline Socioeconomic variable & & $\mathbf{N}$ & Proportion (\%) \\
\hline Gender & Male & 254 & 78.4 \\
\hline & Female & 70 & 21.6 \\
\hline Respondents Age & $18-25$ & 29 & 9.0 \\
\hline & $26-35$ & 84 & 25.9 \\
\hline & $36-45$ & 130 & 40.1 \\
\hline & $46-55$ & 51 & 15.7 \\
\hline & $56-65$ & 22 & 6.8 \\
\hline & $>65$ & 8 & 2.5 \\
\hline Marital Status & Married & 280 & 86.4 \\
\hline & Single & 30 & 9.3 \\
\hline & Widower/Widowed & 8 & 2.5 \\
\hline & Separated/Divorced & 6 & 1.9 \\
\hline & None & 27 & 9.2 \\
\hline & Primary & 179 & 60.9 \\
\hline & Secondary & 68 & 23.1 \\
\hline & Certificate & 14 & 4.8 \\
\hline & Diploma & 5 & 1.7 \\
\hline & Undergraduate & 1 & 0.3 \\
\hline & None & 27 & 9.2 \\
\hline & Primary & 179 & 60.9 \\
\hline & Secondary & 68 & 23.1 \\
\hline
\end{tabular}




\begin{tabular}{|c|c|c|c|}
\hline & Certificate & 14 & 4.8 \\
\hline & Diploma & 5 & 1.7 \\
\hline & Undergraduate & 1 & 0.3 \\
\hline & $<3$ & 32 & 9.9 \\
\hline HH Size & $4-7$ & 167 & 51.5 \\
\hline & $8-10$ & 76 & 23.5 \\
\hline & $11-13$ & 30 & 9.3 \\
\hline & $14-17$ & 14 & 4.3 \\
\hline & $>18$ & 5 & 1.5 \\
\hline & Fisherman/Fisher folk & 158 & 48.8 \\
\hline & Fish traders/fish monger & 84 & 25.9 \\
\hline & Boat owners & 48 & 14.8 \\
\hline & Local gear makers/repairers & 28 & 8.6 \\
\hline & Fishing and equipment dealers & 6 & 1.9 \\
\hline & Luhya & 277 & 85.5 \\
\hline & Luo & 41 & 12.7 \\
\hline & Other & 4 & 1.2 \\
\hline & Somali & 1 & 0.3 \\
\hline & Kalenjins & 1 & 0.3 \\
\hline
\end{tabular}

\section{Chi test of independence}

Finding from the study showed that the chi-square test of independence on awareness of fisheries policies was independent of household size $(\chi 2=28.30 ; \mathrm{df}=10 ; \mathrm{p}=0.002)$ and gender $(\chi 2=6.32 ; \mathrm{df}=2 ; \mathrm{p}=0.044)$ but was dependent on the respondent's age $(\chi 2=110 ; \mathrm{df}=102 ; \mathrm{p}=0.276)$.

Monthly income from fisheries and non-fisheries activities The study's findings showed that more than three-quarters of the respondents earned a monthly income of 1-10,000 Ksh as shown in Table 3. The monthly income range of 0-100,000 Ksh per month. The variation could also be attributed to the type of fisher and fishing gears. Nonetheless, the income range indicates that the fisher community earns a significant amount from the fisheries but cannot appropriately mobilize their profits and lacks a saving and investment culture. For example, the fishing community might establish a local financial institution, where a saving culture could be promoted through a beach Sacco and money could be loaned at low interest rates. Fishermen have a number of disadvantages in their pursuits. For instance, gears required by the government are pretty costly, and theft of equipment is rampant around the lake. The disparity in incomes for the fisher could be explained by the fact that most fishers fish in shallow water, where they get low catches compared to their counterparts with engines and bigger boats who fish in open water and attain more catches.

Table 3: Monthly income from fisheries

\begin{tabular}{|c|c|c|}
\hline $\begin{array}{c}\text { Monthly income from } \\
\text { fisheries (Ksh) }\end{array}$ & Frequency & Percent \\
\hline 1- Nil & 3 & 0.9 \\
\hline 2- 1-10,000 & 245 & 75.6 \\
\hline 3- 10,001-25,000 & 53 & 16.4 \\
\hline 4- 25,001-50,000 & 20 & 6.2 \\
\hline 5- 50,001-100,000 & 3 & 0.9 \\
\hline
\end{tabular}

Note: 1 Ksh. (Kenyan shilling) is approximately equal to USD .01.

According to theory, the fisher community surrounding Lake Victoria is considered the poorest group of individuals in all sectors of the economy. According to the findings, $61.1 \%$ of respondents have no other source of income besides fishing. Those who work in agriculture do so for the primary purpose of subsistence, and their produce is not sold on the market. This clearly demonstrates that poverty among fishermen may be attributable to a lack of alternative economic sources.

Table 4: Monthly income from non-fisheries activities

\begin{tabular}{|c|c|c|}
\hline $\begin{array}{c}\text { Monthly income from } \\
\text { non-fisheries activities }\end{array}$ & Frequency & Percent \\
\hline 1- Nil & 198 & 61.1 \\
\hline 2- 1-10,000 & 94 & 29.0 \\
\hline 3- 10,001-25,000 & 21 & 6.5 \\
\hline 4- 25,001-50,000 & 10 & 3.1 \\
\hline 6- 100,001-200,000 & 1 & 0.3 \\
\hline
\end{tabular}

Note: $1 \mathrm{Ksh}$. (Kenyan shilling) is approximately equal to USD .01.

\section{Econometric results}

Before performing regression analysis, the Variance Inflation Factors (VIF) was used to test for multicollinearity of the independent variables. When the variance inflation factors exceed 10 or the tolerance levels (typically the reciprocal of the variance inflation factors values) are less than 0.10, multicollinearity is a concern. To study each variable's behavior, the independent variables that exhibited a $10 \%$ or less association with the chosen outcome variables were included in estimations. Compliance was evaluated using three key measures: closed seasons, mesh size and beach seining. Beach seining was suppressed. Closed seasons and mesh size thus formed the primary measures (dependent variables). The legitimacy variable is a significant variable that impacts compliance based on literature review. Legitimacy refers to the overall acceptance of these regulations and the community's benefit from fishing laws. This variable, which is structurally crucial in the compliance theory, was not significant in any of the models provided, as indicated in Table 5. The fact that this variable has no importance is key to comprehending the setting of the current investigation. The overlapping duties could explain this among the various authorities and lack of clarity about enforcement activities.

According to Eggert and Lokina ${ }^{[18]}$, a financial incentive to break the regulations is one of the features or incentives that can make a fisherman more inclined to break the rules to increase revenue. In this study, the financial characteristic was significant in the regressions. This implies that fishermen who earn money from sources other than fishing are less likely to break the rules. When asked if they were willing to accept sustainable alternative livelihoods, most respondents (91\%) agreed. As a result, the focus should shift to viable, 
sustainable alternative livelihood activities to the riparian population, such as farming, aquaculture, and other economic activities. The communities living near the lake will rely less on the lake's fisheries due to this. This will help to ensure that the lake's fisheries resources are conserved and used sustainably. Given the depleting fish resource, Cressey [19] believes that sustainable aquaculture is critical for shifting to commercially and environmentally beneficial fish production. Aquaculture has been reported to produce opportunities for the skilled and non-skilled, as well as employment in new supporting industries, in Uganda ${ }^{[20]}$ and Egypt ${ }^{[21]}$.

Finally, knowledge was also significant. Nonetheless, it exhibits a positive relationship, implying that the offenders have a better understanding of what the regulations are yet still violate.

Table 5: Econometric estimations

\begin{tabular}{|c|c|c|}
\hline & Closed seasons & mesh size \\
\hline Age & $-0.0167(-1.17)$ & $-0.01516(-1.2)$ \\
\hline Knowledge & $0.7276(2.12)^{* *}$ & $0.513715(2.25)^{* *}$ \\
\hline Financial & $-0.291012(-1.2)^{* *}$ & $-0.39214(-1.57)^{* *}$ \\
\hline Legitimacy & $-0.58109(-2.11)$ & $-0.11176(-0.48)$ \\
\hline OthersViolation & $2.036236(2.26)^{* *}$ & $2.061127(2.18)^{* *}$ \\
\hline Constant & $1.7545(1.59)$ & $0.86375(0.49)$ \\
\hline $\mathrm{N}$ & 324 & 324 \\
\hline Pseudo R $^{2}$ & 0.51 & 0.43 \\
\hline$P>$ Chi $^{2}$ & 0.0001 & 0.0001 \\
\hline
\end{tabular}

$\mathrm{Z}$ values in parenthesis $* * * p<0.1, * * p<0.05, * p<0.1$ respectively

The marginal effects for the statistically significant variables are presented in Table 6 . The financial variable shows the expected sign. Higher values, like having more stable source of income, imply a decreased probability of violating the closed seasons and mesh size regulation. Others' violating show that higher values, like the perception of more people violating, imply an increased probability of breaking the closed seasons and mesh size regulation. The effect of knowledge on the probability of violating specific regulations is positive, implying an increased probability of violating.

Table 6: Marginal effects of the significant variables for each model

\begin{tabular}{|c|c|c|}
\hline Variable & Closed seasons & Mesh size \\
\hline Knowledge & $0.210^{* *}$ & $0.16^{* *}$ \\
\hline Financial & $-0.176^{* *}$ & $-0.193^{* *}$ \\
\hline OthersViolation & $0.61^{* *}$ & $0.52^{* *}$ \\
\hline
\end{tabular}

\section{Conclusions}

This study investigated the effect of fisheries policy implementation strategies on regulatory compliance in the small-scale fisheries sector in Lake Victoria, in Busia County, Kenya. The variable legitimacy, which is structurally crucial in the compliance theory, was not significant in any of the models. The fact that this variable has no importance is key to comprehending the setting of the current investigation. The overlapping duties among the various authorities and lack of clarity about enforcement activities could explain this. Examining the fishery's specific conditions is required to debate the importance of non-recognized regulations, why this happens, and how to strengthen the procedures to make them legal. The study revealed that people who are more aware of the rules on closed seasons and mesh size are also more likely to break them. This fact should motivate policymakers to focus their efforts on educating the public better about the regulations. Finally, as the results show, when a fisher's income is more consistent, he is less likely to violate the regulations of closed seasons and mesh size. Stronger political will and government commitment are required to implement long-term alternative livelihood strategies to increase compliance and quality of life.

\section{Acknowledgments}

The authors wish thank the research assistants who did a commendable job in the quest for data and the resource persons who provided valuable and useful insights.

\section{References}

1. Ogello EO, Obiero K, Munguti JM. Lake Victoria and The Common Property Debate: Is the Tragedy of the Commons a threat to its future? Lakes Reservoirs and Ponds 2013;7(2):101-126.

2. World Bank. Linking Poverty Reduction and Environmental Management: Policy Challenges and Opportunities, Washington DC, World Bank 2002.

3. UNEP, State of the Environment and Policy Retrospective: 1972-2002. 2002.

4. Kimani EN, Aura MC, Okemwa GM. (eds.). The Status of Kenya Fisheries: Towards the sustainable exploitation of fisheries resources for food security and economic development. Kenya Marine and Fisheries Research Institute (KMFRI), Mombasa 2018, 135.

5. Odoli C, Owiti H, Kobingi N, Obiero M, Ogari Z, Mugo $\mathrm{J}$, et al. Post-harvest interventions in small-scale fisheries: A boon or a bane to food and nutritional security in Kenya? Journal of Food Security 2019;11:855-868.

6. Kenya Bureau of National Statistics. Economic Survey 2021.

7. Obiero K, Meulenbroek P, Drexler S, Dagne A, Akoll P, Odong $\mathrm{R}$ et al. The contribution of fish to food and nutrition security in Eastern Africa: Emerging trends and future outlooks. Sustainability 2019;11(6):1636.

8. Kenya Bureau of National Statistics. Economic Survey 2020. https://www.knbs.or.ke/?wpdmpro=economicsurvey-2020 02

9. LVFO. Fisheries Management Plan III (FMPIII) for Lake Victoria fisheries 2016-2020. Jinja, Uganda LVFO Secretariat 2016.

10. Graham M. The Victoria Nyanza and its Fisheries: A Report on the Fishing Survey of Lake Victoria, 19271928, and Appendices. Crown Agents for the colonies 1929.

11. County Government of Busia. Directorate of Fisheries 2021. https://busiacounty.go.ke/main/index.php/fisheries. 28 September, 2020.

12. Eggert H, Razack BL. Regulatory compliance in Lake Victoria fisheries. Environment and Development Economics 2010;15(2):197-217.

13. Etiegni CA, Ostrovskaya E, Leentvaar J, Eizinga F. Mitigation of illegal fishing activities: enhancing compliance with fisheries regulation in Lake Victoria (Kenya). Regional Environmental Change 2011;11(2):323-334.

14. Kenya institute for public policy research and analysis. Busia County integrated development plan 2018-2022 2021.

http://repository.kippra.or.ke/handle/123456789/1200

15. Kenya National Bureau of Statistics 2019 Kenya Population and House Census: Population by County and 
Sub-county. Kenya National Bureau of Statistics 2019;1:9, 10, 19. ISBN 9789966102096.

16. Awuor FJ, Obiero K, Munguti J, Oginga JO, Kyule D, Opiyo MA et al. Market linkages and distribution channels of cultured, captured and imported fish in Kenya. Aquaculture Studies 2019;19(1):57-67.

17. Yongo EO, Lwenga C, Miahangwe E, Kaidhiwa $M$. Governance and welfare of fishing communities of Lake Victoria 2013.

18. Eggert H, Lokina RB. Small-scale fishermen and risk preferences. Marine Resource Economics 2007;22(1):4967.

19. Cressey D. Aquaculture: future fish. Nature News 2009;458(7237):398-400.

20. Mbowa S, Odokonyero T, Munyaho A. Harnessing floating cage technology to increase fish production in Uganda 2017, 677-2017-4156.

21. Soliman NF, Yacout DM. Aquaculture in Egypt: status, constraints and potentials. Aquaculture international 2016;24(5):1201-1227. 